
\title{
R Research S Suare \\ Facile Techniques to Synthesize Reduced Graphene Oxide for Removing Tetracycline From Water: Kinetics and Thermodynamics Studies
}

Trinh Tran Dinh ( $\nabla$ trinhtd@vnu.edu.vn )

University of Science https://orcid.org/0000-0001-9936-1823

Thi-My-Trinh Ha

University of Science

Thi-An-Hang Nguyen

Viet Nam Japan University

Viet-Cuong Dang

University of Science

Van-Duong Dao

Phenikaa University

Research Article

Keywords: Tetracycline, adsorption, influencing parameters, thermodynamics, kinetics, regeneration

Posted Date: October 1st, 2021

DOl: https://doi.org/10.21203/rs.3.rs-950512/v1

License: (c) (i) This work is licensed under a Creative Commons Attribution 4.0 International License.

Read Full License 


\section{Facile techniques to synthesize reduced graphene oxide for removing tetracycline} from water: kinetics and thermodynamics studies

\section{Dinh-Trinh Tran",*, Thi-My-Trinh Ha ${ }^{1}$, Thi-An-Hang Nguyen², Viet-Cuong Dang1, Van- Duong Dao ${ }^{3}$ \\ ${ }^{1}$ VNU Key Lab. of Advanced Materials for Green Growth, University of Science, Vietnam} National University, Hanoi, No. 19 Le Thanh Tong St., Hoan Kiem Dist., Hanoi, 11021, Vietnam

${ }^{2}$ Viet Nam Japan University (VNU-VJU), Vietnam National University, Hanoi, Luи Hии Phиос St., Nam Tu Liem Dist., Hanoi, 101000, Vietnam

${ }^{3}$ Faculty of Biotechnology, Chemistry and Environmental Engineering, Phenikaa University, Hanoi, 10000, Vietnam

\section{*Corresponding author: Dinh-Trinh Tran}

Email: trinhtd@vnu.edu.vn

\section{Abstract}

In this study, reduced graphene oxide (rGO) was successfully produced from graphite precursor by chemical oxidation and exfoliation processes which were followed by a reduction process in mild conditions. rGO was then applied in the adsorption of tetracycline (TC) in water. SEM/EDX, XRD, FT-IR, BET, $\mathrm{pH}_{\mathrm{pzc}}$ were conducted to characterize the synthesized materials. The adsorption efficiency of TC from water was evaluated by changes in several factors such as contact time, temperature, $\mathrm{pH}$ of the solution, adsorbent load, and tetracycline concentration. Furthermore, adsorption kinetics, thermodynamics, and isotherms were also investigated. As the result, the adsorption process of $\mathrm{TC}$ onto $\mathrm{rGO}$ was spontaneous, endothermic, and governed by 
25 both physisorption and chemisorption. The maximum uptake calculated from Langmuir isotherm

26 model was $58.03 \mathrm{mg} / \mathrm{g}$. rGO material could be regenerated by using methanol and diluted $\mathrm{NaOH}$

27 solutions. The findings in this work provides a complete data on the TC adsorption process onto

$28 \mathrm{rGO}$ and the process of recovery and reuse of rGO.

Keywords: Tetracycline, adsorption, influencing parameters, thermodynamics, kinetics, regeneration.

\section{Introduction}

Since their discovery in 1928, antibiotics have played a very important role in human health protection and the livestock industry. They have been extensively and effectively used in human and veterinary medicines and their benefits have also been recognized in agriculture, aquaculture,

37 bee-keeping, and livestock as growth promoters [1]. It is estimated that millions of people have been saved from diseases (smallpox, cholera, typhoid fever, syphilis, etc.) thanks to antibiotics.

Intensive use of antimicrobials in livestock is a global trend. Van Boeckel et al. [2]

40 estimated that global consumption of antimicrobials in animal food production was 63,151

$41( \pm 1,560)$ tons in 2010 , then doubled in 2013 ( 131.109 tons) and expected to reach 200,235 tons

42 by $2030[2,3]$. The increasing usage of antibiotics raised a concern about the effect of their residue

43 to the environment and human health. Beek et al. [4] collected data from more than 1000

44 publications about pharmaceutical concentrations and found that pharmaceuticals in the

45 environment were truly a topic of global concern when it detected in 71 countries all around the

46 world. The antibiotic - containing wastewater is the main factor contributing to the promotion of

47 bacterial resistance genes, antibiotic resistant bacteria and some allergic reactions in human and 
48 animals $[5,6]$. Antibiotic-resistant infections also contribute to the financial burden on healthcare 49 systems.

Tetracycline (TC) antibiotics are one of the primarily antibiotics groups used for veterinary

51 purposes, for human therapy and in agriculture sector as feed additive [7]. According to Chen et

52 al. [8] tetracyclines are ranked second in the production and usage of antibiotics worldwide and

53 are ranked first place in China. Tetracycline is high water solubility $(0.041 \mathrm{mg} / \mathrm{L})$ and low volatility

54 (low $\log$ Kow). Therefore, it likely is persistent in the aquatic environment. Tetracycline was 55 detected $0.151 \mu \mathrm{g} / \mathrm{L}$ (median) and $0.977 \mu \mathrm{g} / \mathrm{L}$ (maximum) in wastewater treatment plants [9] and 56 municipal wastewater treatment plants effluent samples [10].

57 Several techniques have been developed to efficiently and effectively remove TC residues 58 from water such as membrane filtration [11] adsorption [12], and advanced oxidation processes 59 [13-16]. Among these methods, adsorption was a simple treatment method; it was affordable, easy 60 to handle with simple equipment, and low cost. In addition, the adsorbent could be recycled and 61 able to reuse several times. There were various mechanisms that affect the accumulation of 62 adsorbates on the surface of adsorbent like $\pi-\pi$ interaction, electrostatic interaction, and pore63 filling mechanism $[17,18]$.

Graphene is a single layer of carbon with thickness as a carbon molecule, dense with $\mathrm{sp}^{2}$ 65 carbon molecules in honeycomb lattice [19]. Graphene oxide (GO) is oxidized graphene and has 66 the presence of oxygen-containing functional groups while reduced graphene oxide (rGO) is 67 obtained from the reduction of GO by removing oxygen-containing functional groups. There were 68 69 70 differences in functional groups or $\mathrm{C}: \mathrm{O}$ ratio between $\mathrm{GO}$ and $\mathrm{rGO}[20,21]$. Although the presence of oxygen-containing groups make GO able to be hydrophilic which is suitable for water treatment, they usually weaken the $\pi$-electron activity linked to a high fraction of $\mathrm{sp}^{3} \mathrm{C}$ atoms, which is 
71 important interaction in the adsorption process [20]. On the other hand, rGO had a large specific

72 surface area and significantly fewer functional groups than GO [22, 23]. Therefore, rGO is a

73 promising adsorbent for the treatment of different pollutants. Huízar-Félix et al. [24] reported

74 about the removal of $\mathrm{TC}$ using magnetic $\mathrm{rGO}$ material, which was expected to increase

75 electrostatic interaction between $\mathrm{rGO}$ with the TC and recoverability. rGO also showed a rather

76 high adsorption capacity for TC/sulfamethazine mixture $(277.76 \mathrm{mg} / \mathrm{g})$ than each substance

77 (219.10mg/g for TC and $174.42 \mathrm{mg} / \mathrm{g}$ for sulfamethazine) [25]. However, there is a lack of research

78 conducting a complete study on the effect of different parameters on the adsorption of TC by rGO,

79 which provide fully information of the adsorption of TC by rGO.

This paper aims to synthesize rGO from graphite precursor by chemical reduction of GO

81 using L-ascorbic acid and employ rGO material to study the TC adsorption process. The effect of

82 cintact time, temperature, initial $\mathrm{pH}$, adsorbent dosage, initial TC concentration, and stability and

83 reusability of the material will be investigated. Furthermore, the adsorption isotherms, adsorption

84 kinetics, adsorption thermodynamics will be reported.

\section{Experimental}

\section{2.1. Chemicals}

Tetracycline powder (95.3\% purity) were purchased from LKT Laboratories, Inc (Japan).

89 Tetracycline stock solutions $(100 \mathrm{mg} / \mathrm{L})$ were prepared by dissolving TC powder in double distilled

90 water and stored at $4^{\circ} \mathrm{C}$. Graphite fine powder extra pure were obtained for Merck (Germany).

91 Concentrated sulfuric acid $\left(\mathrm{H}_{2} \mathrm{SO}_{4}\right)$, sodium nitrate $\left(\mathrm{NaNO}_{3}\right)$, potassium permanganate $\left(\mathrm{KMnO}_{4}\right)$,

92 hydrogen peroxide $\left(\mathrm{H}_{2} \mathrm{O}_{2}\right)$, hydrochloric acid $(\mathrm{HCl})$, L-ascorbic acid $\left(\mathrm{C}_{6} \mathrm{H}_{8} \mathrm{O}_{6}\right)$, nitric acid $\left(\mathrm{HNO}_{3}\right)$, 
93 and sodium hydroxide $(\mathrm{NaOH})$ were purchased from Xilong Scientific Co., Ltd. (China). All of

94 the reagents used were of analytical grade.

\subsection{Preparation of reduced graphene oxide}

GO was synthesized by using modified Hummer's methods [15, 16]. The oxidation of graphite was conducted with the mixture of $\mathrm{KMnO}_{4}, \mathrm{H}_{2} \mathrm{SO}_{4}, \mathrm{NaNO}_{3}$. The obtained product was washed several times with doubly distilled water and then dried at $50^{\circ} \mathrm{C}$ overnight.

rGO was synthesized by the chemical reduction method using L-ascorbic acid. 1 gram of L-ascorbic acid is dissolved in $100 \mathrm{ml}$ of distilled water. After adding $0.1 \mathrm{~g}$ of GO, the mixture was ultrasonicated in 45 minutes, then heated to $90 \sim 95^{\circ} \mathrm{C}$ for 1 hour. After the reaction time, the black precipitate was filtered by a vacuum pump and further washed by $1 \mathrm{M} \mathrm{HCl}$ and doublydistilled water until a neutral $\mathrm{pH}$ value was achieved. Finally, the solid product was dried in a vacuum oven at $60^{\circ} \mathrm{C}$ for 4 hours.

\subsection{Characterization of rGO material}

X-ray powder diffraction (XRD) patterns were analyzed by X-ray diffraction spectroscopy (Miniflex 600, Rigaku, Japan) using $\mathrm{Cu} \mathrm{K \alpha}$ radiation source $(\lambda=1.5418 \AA$ ) operated at a scan rate of $0.03^{\circ} . \mathrm{s}^{-1}$ within a $2 \theta$ range from $5^{\circ}-70^{\circ}$. Surface morphology and elemental composition of the material were performed by JSM-IT100/JED-2300 Analysis station, JEOL. Fourier Transform Infrared Spectroscopy (FT-IR) were recorded on an IR spectrometer Jasco 4600 (Japan) with a resolution of $4 \mathrm{~cm}^{-1}$ in the range of $400-4000 \mathrm{~cm}^{-1}$ at room temperature. Surface areas of the synthesized materials were measured by the Brunauer-Emmett-Teller method performed by a NOVAtouch $\mathrm{LX}^{4}$. The point of zero charges of the sample was examined by $\mathrm{pH}$ drifting method as presented in our previous work [16]. The calculation of crystalline particles from XRD data, the

$$
\text { Debye - Scherrer equation was used as follows: }
$$




$$
D=\frac{0.9 \cdot \lambda}{\beta \cdot \cos \theta}
$$

117 where $\lambda$ is the $\mathrm{X}$-ray wavelength of $\mathrm{Cu}-\mathrm{K} \alpha$ radiation source $(\lambda=0.15418 \mathrm{~nm}), \beta$ (in radians) is the

118 full width at half maximum (FWHM) intensity of the diffraction peak located at $2 \theta$, and $\beta$ is the 119 Bragg angle.

\subsection{Batch experiments}

122 TC solution was prepared from $1000 \mathrm{mg} / \mathrm{L}$ TC stock solution then transferred to a conical flask.

123 Subsequently, $10 \mathrm{mg}$ of the rGO material was added to the solution. The mixture was shaken at $124120 \mathrm{rpm} .2 \mathrm{~mL}$ of solution was sampled at an interval time of 1 hour, filtered to determine the 125 remaining TC concentration in the solution by UV-Vis spectroscopy (model UH5300/Hitachi, 126 Japan) at an optimal wavelength of $358 \mathrm{~nm}$. To evaluate the impact of solution $\mathrm{pH}$ on the 127 adsorption efficiency of $\mathrm{rGO}$, the $\mathrm{pH}$ value of the examined solutions was adjusted within the 128 range of 2 to 10 while other conditions were unchanged. The impact of adsorbent dose on the 129 adsorption efficiency of rGO was examined by varying rGO concentrtion from $50 \mathrm{mg} / \mathrm{L}$ to 250 $130 \mathrm{mg} / \mathrm{L}$, and keeping other parameters unchanged. Similarly, the influence of initial TC 131 concentrations on $\mathrm{rGO}$ adsorption efficiency was tested within the range of $5 \mathrm{mg} / \mathrm{L}$ to $80 \mathrm{mg} / \mathrm{L}$. 132 Finally, the impact of temperature was examined with three temperature $298 \mathrm{~K}, 308 \mathrm{~K}$, and $318 \mathrm{~K}$. 133 It is noted that all the experiments were conducted in triplicate.

\subsubsection{Adsorption isotherm models}

135 The adsorption uptake for TC removal $q_{\mathrm{t}}(\mathrm{mg} / \mathrm{g})$ at time $t$ was calculated by the equation (1):

$$
q_{t}=\frac{\left(C_{0}-C_{t}\right) \cdot V}{m}
$$


137 where $C_{0}(\mathrm{mg} / \mathrm{L})$ and $C_{\mathrm{t}}(\mathrm{mg} / \mathrm{L})$ are the TC initial concentrations and at time $t(\mathrm{~min})$, respectively.

$138 V$ is the volume of TC solutions $(\mathrm{L}) ; m$ is $\mathrm{rGO}$ mass $(\mathrm{g})$.

139 The Langmuir (Eq. 3) and Freundlich (Eq. 4) are the two most commonly used isotherm models

140 for describing the adsorption of pollutants onto graphene-based adsorbents [26].

$$
\begin{aligned}
& q_{e}=\frac{q_{\max } \cdot b \cdot C_{e}}{\left(1+b \cdot C_{e}\right)} \\
& q_{e}=K \cdot\left(C_{e}\right)^{n}
\end{aligned}
$$

143 where $q_{\max }$ is the Langmuir maximum uptake $(\mathrm{mg} / \mathrm{g}), C_{\mathrm{e}}$ is the equilibrium solution sorbate 144 concentration $(\mathrm{mg} / \mathrm{L})$, and $\mathrm{n}$ is the Freundlich linearity constant. $b$ and $K$ designate the Langmuir 145 bonding term related to the interaction energies $(\mathrm{L} / \mathrm{mg})$ and the Freundlich affinity coefficient $146 \quad\left(\mathrm{~L}^{\mathrm{n}} \cdot \mathrm{mg}^{(1-\mathrm{n})} / \mathrm{g}\right)$, respectively.

147 The Langmuir model supposes homogeneous binding sites, with equivalent sorption energies, 148 and no interaction between adsorbed pollutants whereas the Freundlich is an empirical model 149 related to an exponential distribution of adsorption sites and energies. The parameters obtained 150 from the Langmuir and Freundlich models reveal important information on the surface property 151 and affinity of the adsorbent as well as the sorption mechanism. In this report, the experimental 152 data is fitted with Langmuir and Freundlich isotherm models by using OriginLab software version 1539.0 , OriginLab Corporation).

\subsubsection{Adsorption kinetics modeling}

155 In this work, pseudo-first-order, pseudo-second-order, and intra-particle diffusion models were 156 deployed to examine the adsorption kinetics. They can be written as the following where the

157 pseudo-first-order, pseudo-second-order, and intra-particle diffusion models are presented in 158 equations 5,6 , and 7 , respectively.

$$
\ln \left(q_{e}-q_{t}\right)=\ln q_{e}-K_{1} \cdot t
$$




$$
\frac{t}{q_{t}}=\frac{1}{K_{2} \cdot q_{e}^{2}}+\frac{t}{q_{e}}
$$

$$
q_{t}=K_{3} \cdot t^{1 / 2}+C
$$

162 where $q_{e}$ and $q_{t}$ are the adsorption uptake of TC at equilibrium and at time $t$ (min) while $K_{1}$

$163(1 / \mathrm{min})$ is the adsorption rate constant, $K_{2}(\mathrm{~g} / \mathrm{mg} \cdot \mathrm{min})$ is the rate constant of the second-order 164 model, $K_{3}\left(\mathrm{mg} / \mathrm{g} \cdot \mathrm{min}^{1 / 2}\right)$ is the rate constant of the intra-particle diffusion model, and $C$ is the 165 intercept.

166 These kinetics models were evaluated in terms of the normalized standard deviation $\Delta q(\%)$, 167 which is calculated as:

$$
\Delta q(\%)=\frac{\left(q_{e, e x p}-q_{e, c a l}\right)}{q_{e, \exp }} \cdot 100
$$

\subsubsection{Adsorption thermodynamics modeling}

170 Thermodynamic characteristics of TC adsorption processes onto rGO were evaluated by 171 thermodynamic parameters which involved changes in Gibbs free energy $(G)$, enthalpy $(H)$, and 172 entropy $(S)$. These parameters can be expressed as follows:

$$
\begin{aligned}
& \Delta G=-R T \ln \left(K_{d}\right) \\
& K_{d}=\frac{q_{e}}{C_{e}} \\
& \Delta G=\Delta H-T \cdot \Delta S \\
& \ln \left(K_{d}\right)=\frac{\Delta S}{R}-\frac{\Delta H}{R T}
\end{aligned}
$$

177 where $R$ : the universal gas constant $=8.314(\mathrm{~J} / \mathrm{mol} \mathrm{K}), T$ : the temperature $(\mathrm{K})$, and $K_{d}$ : the 178 distribution coefficient for the adsorption of TC.

\subsubsection{Regeneration of the adsorbent}

The regeneration of adsorbent is an important factor to evaluate the application of the process

181 in reality. In this work, three successive cycles of adsorption-desorption were conducted. rGO 
182 adsorbent was first washed several times with methanol 99.6\%, then shaken in $0.1 \mathrm{M} \mathrm{NaOH}$ 183 solution for 12 hours. In the subsequent step, the adsorbent was washed with distilled water to 184 reach pH7 (verification by a pH meter HI2210-02, Hanna Instruments) prior to using for the next 185 adsorption experiment.

187 3. Results and discussion

\subsection{Characterization of materials}

The XRD patterns of rGO, GO, and graphite are presented in the Fig 1 . It can be clearly seen that characteristic peaks of graphite at $2 \theta=26.6^{\circ}$ and $54^{\circ}$. The peak at $26.6^{\circ}$ was shifted to

$19110.62^{\circ}$, characterizing the presence of GO crystalline structure $[17,24,15]$, indicated that the 192 graphite was fully oxidized. The broaden peak for rGO at $2 \theta=24.6^{\circ}$ implied that the rGO structure 193 was arranged randomly, resulting in the formation of a single or only a few layers of rGO. A weak 194 intensity peak at $2 \theta=42.88^{\circ}$ might be attributed to the turbostratic structure of disordered carbon 195 materials $[16,29,30]$.

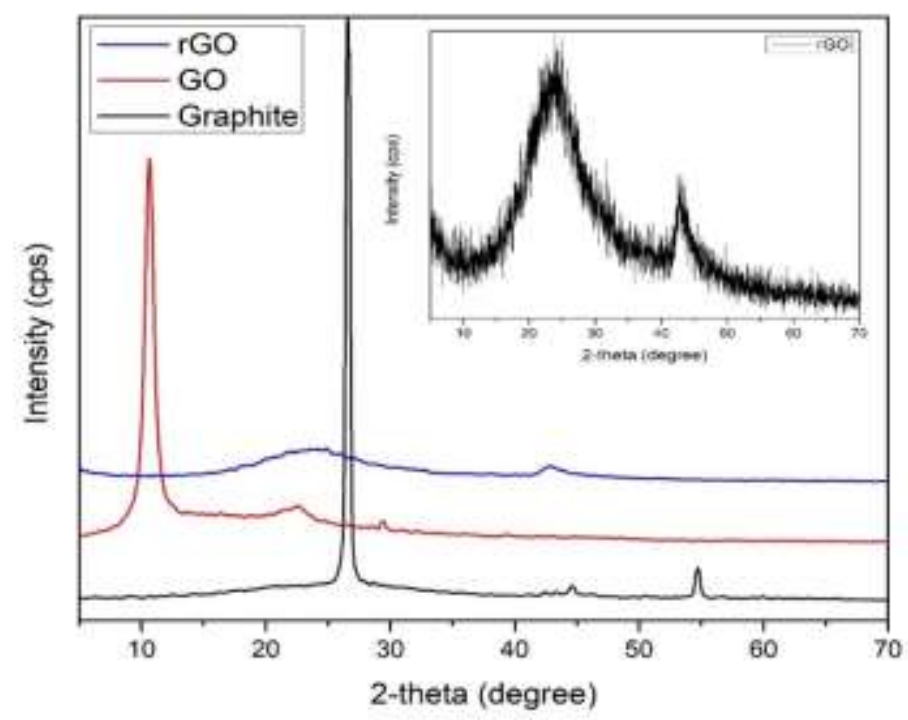

Fig. 1 XRD pattern of graphite, GO, and rGO materials. 
The interlayer distance of GO was $8.33 \AA$, which was 2.5 times higher than the interlayer distance of graphite precursor (calculated from Eq.1). This phenomenon might be explained by the insertion of oxygen functional groups in the graphite plate after oxidation [27]. The interlayer distance of rGO was $3.59 \AA$, which was significantly decreased due to the elimination of various oxygen-containing functional groups after the chemical reduction [28].

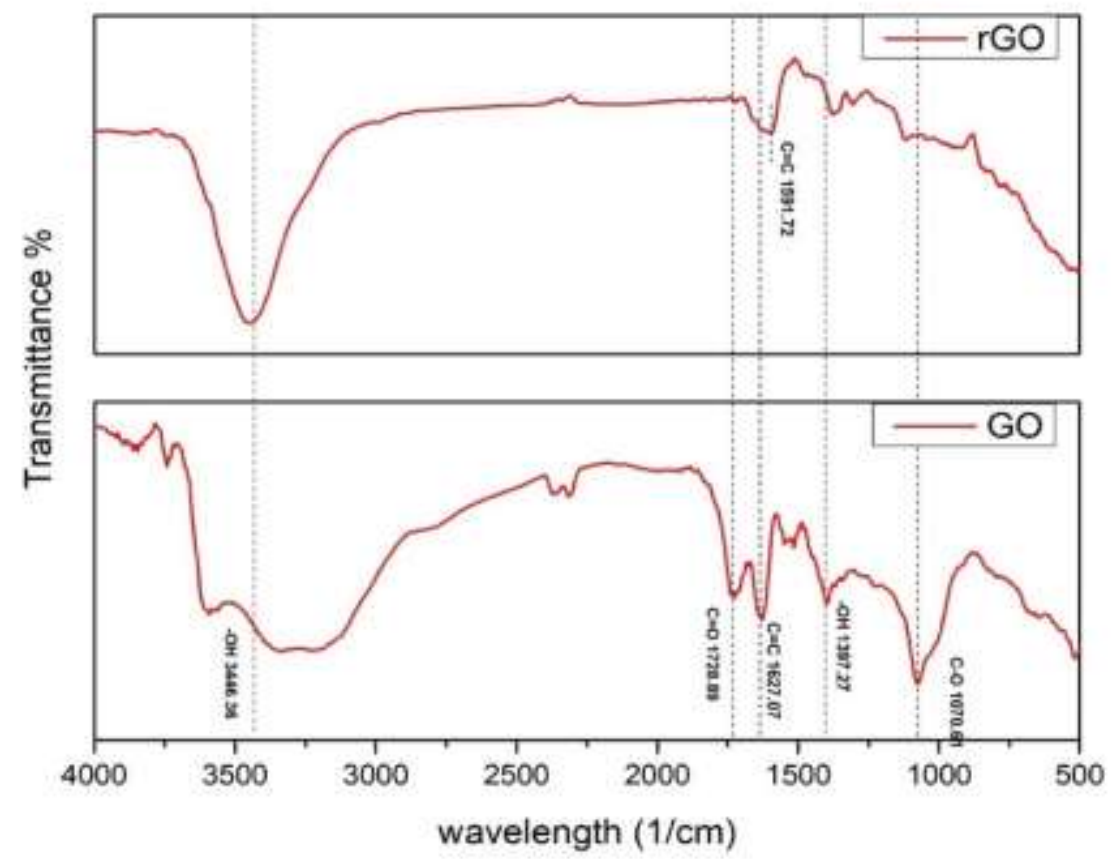

Fig. 2 FT - IR spectrum of GO and rGO materials.

Functional groups of GO and rGO were examined with the aid of the FT-IR method, and several similarities with previous studies, consisted of an intense peak at $3446 \mathrm{~cm}^{-1}$ and other weak intensity peaks at 1728,1627 , and $1070 \mathrm{~cm}^{-1}$, which might be associated with the vibration of O$\mathrm{H}, \mathrm{C}=\mathrm{O}, \mathrm{C}=\mathrm{C}$, and $\mathrm{O}-\mathrm{C}-\mathrm{O}$, respectively $[15,16,31]$. It was noted that the rGO spectrum witnessed 210 a diminish in the intensity of the peak at $1728 \mathrm{~cm}^{-1}, 1397 \mathrm{~cm}^{-1}$, and $1070 \mathrm{~cm}^{-1}$, which indicated the 211 reduction of aldehyde $(\mathrm{C}=\mathrm{O})$ groups, tertiary $\mathrm{C}-\mathrm{OH}$ groups, and alkoxy groups. The appearance 
212 of an intense peak at $1591 \mathrm{~cm}^{-1}$ confirmed the restoration of the $\mathrm{sp}^{2}$ carbon networks [32]. The 213 obtained results suggested the reduction of oxygen-containing groups by L-Ascorbic acid. This 214 observation was also confirmed by the EDX analysis presented in the subsequent section. that the graphite's structure was characterized by several layers stacked while rGO took a typical

217 wrinkled morphology. of toxic gases and/or damage to the product's structure [33].

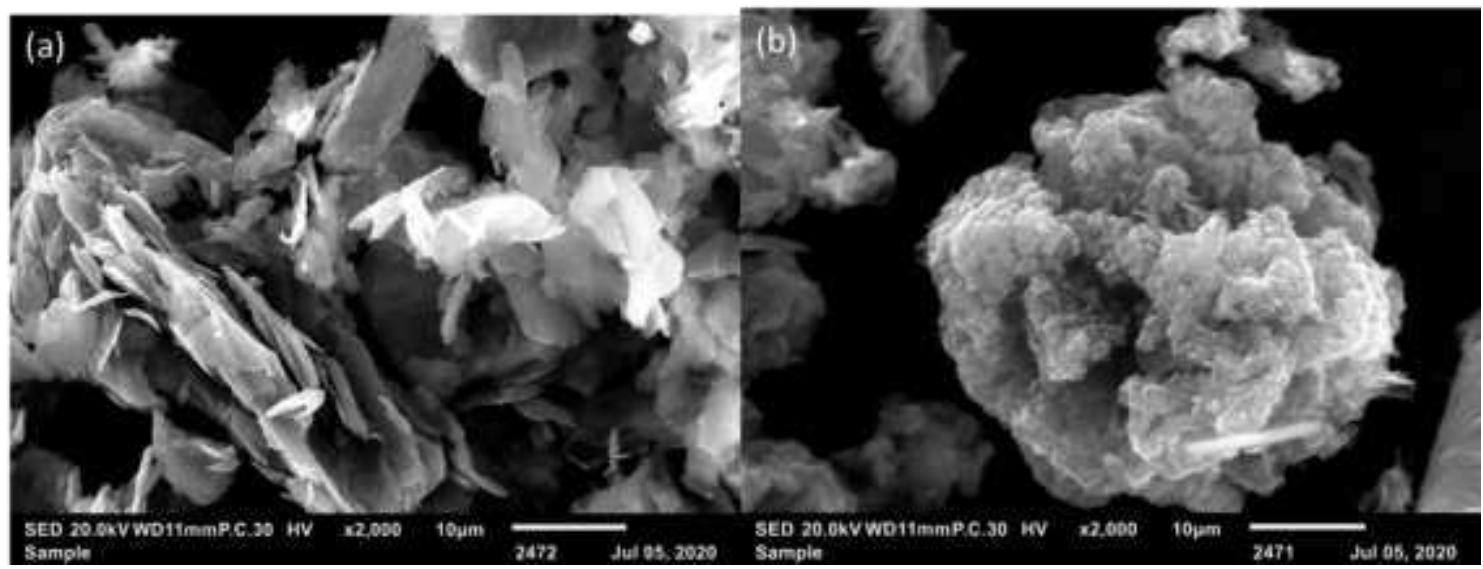

Fig. 3 SEM images of (a) graphite and (b) rGO materials.

The elemental composition of the material was examined by the EDX method. The C/O ratio in GO and rGO materials were respectively 1.07 and 7.10 (Table 1), implying that the removal of oxygen-containing functional groups led to the reduction of oxygen element in the rGO sheets. The obtained results in this work were comparable with previously reported results, which applied different reduction methods (Table 1). It is noted that the reduction of GO by L-ascorbic acid is milder and more acceptable than the use of $\mathrm{NaBH}_{4}$ or hydrazine, which can result in the formation 
Table 1. Elemental composition of materials in this study and previous studies.

\begin{tabular}{|c|c|c|c|}
\hline Material & $\mathrm{C} / \mathrm{O}$ atomic ratio & Reduction agent & References \\
\hline Graphite & 23.75 & \multirow{3}{*}{ L-ascorbic acid } & \multirow{3}{*}{ This study } \\
\hline GO & 1.07 & & \\
\hline $\mathrm{rGO}$ & 7.10 & & \\
\hline Graphite & 17.87 & \multirow{3}{*}{ L-ascorbic acid } & \multirow{3}{*}{ [33] } \\
\hline GO & 2.65 & & \\
\hline $\mathrm{rGO}$ & $2.89-5.15$ & & \\
\hline $\mathrm{rGO}$ & 5.38 & $\mathrm{NaBH}_{4}, \mathrm{CaCl}_{2}$ (catalyst) & [34] \\
\hline GO & 2.23 & \multirow{2}{*}{ Azotobacter chroococcum } & \multirow{2}{*}{ [8] } \\
\hline $\mathrm{rGO}$ & 4.18 & & \\
\hline rGO & $6.87-6.97$ & $\mathrm{NaBH}_{4}$ & [35] \\
\hline $\mathrm{rGO}$ & 15.1 & Hydrazine & [36] \\
\hline $\mathrm{rGO}$ & $2.73-3.64$ & Starch & [37] \\
\hline $\mathrm{rGO}$ & 7.75 & Aluminum powder & [38] \\
\hline
\end{tabular}

The BET analyses are displayed in Fig. 4. The $\mathrm{N}_{2}$ adsorption-desorption isotherm was 233 characterized by type IV and the H3 hysteresis loop [15]. Type IV isotherm was associated with 234 capillary condensation taking place in mesopores, while the H3 hysteresis loop exhibited the aggregates of micropores associated with plate-like particles giving rise to slit-shaped pores [15].

236 The pore-size distribution in rGO presented two typical peaks with a half pore width of $\sim 3.2 \mathrm{~nm}$ 237 and about $12 \mathrm{~nm}$ while most of the pores had a radius below $25 \mathrm{~nm}$, suggesting that synthesized 238 rGO was mesoporous material. The specific surface area of $\mathrm{rGO}$ was $341.2 \mathrm{~m}^{2} / \mathrm{g}$, significantly 239 higher than that of graphite $\left(7.78 \mathrm{~m}^{2} / \mathrm{g}\right)$. The surface area of rGO was quite lower than the 240 theoretical value (around 2,500 $\mathrm{m}^{2} / \mathrm{g}$ ) could be attributed to tight hydrogen bonding and the 241 formation of aggregates from rGO sheets when the solvents were removed [39, 40]. 

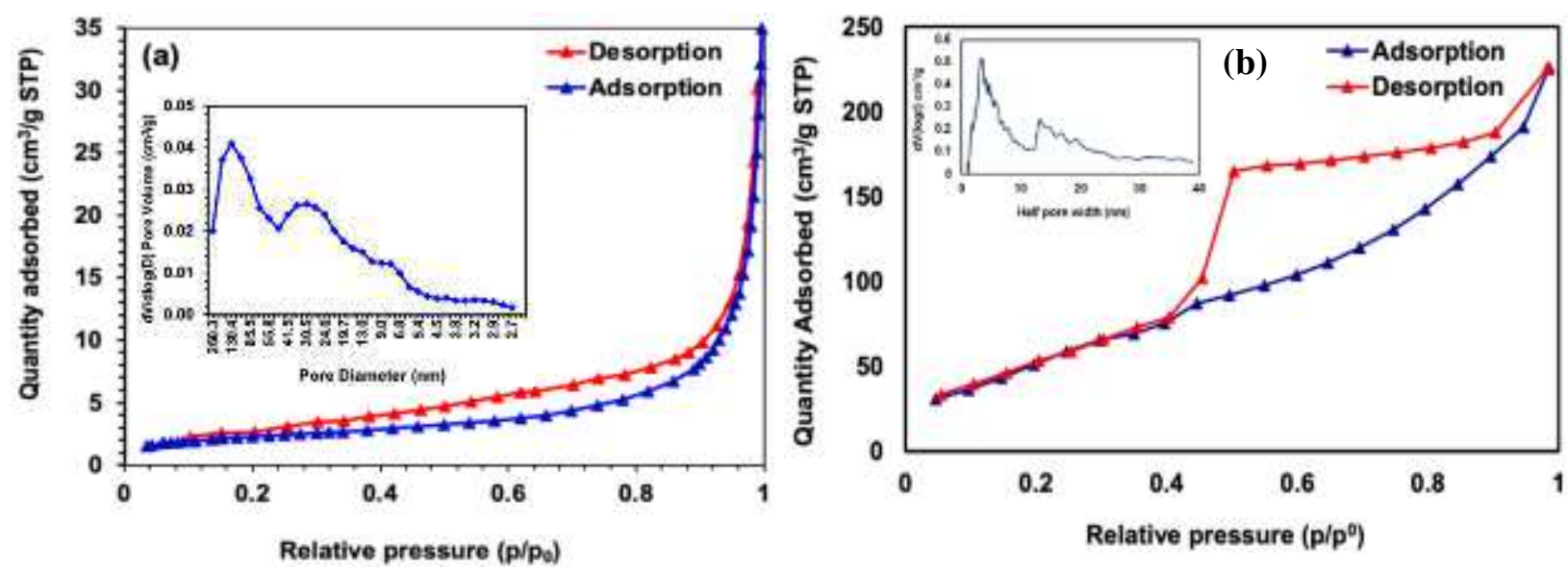

Fig. 4 Nitrogen adsorption - desorption isotherm and pore size distribution of (a) graphite and

(b) rGO samples.

Point of zero charges $\left(\mathrm{pH}_{\mathrm{pzc}}\right)$ is when the surface charge of the material equals zero. In this work, the $\mathrm{pH}_{\mathrm{pzc}}$ of the $\mathrm{rGO}$ material was 5.2, implying that the $\mathrm{rGO}$ surface was positively charged in $\mathrm{pH}<5.2$ solutions while it was negatively charged $\mathrm{pH}>5.2$ solutions.

\subsection{TC adsorption processes onto rGO material}

\subsubsection{Effect of contact time and $\mathrm{pH}$}

The obtained results are shown in Fig. 5. It was clear that the adsorption uptake of rGO quickly increased during the first 6 hours, reached $46.45 \mathrm{mg} / \mathrm{g}$, then remained relatively stable

252 afterward, suggesting that the equilibrium time for the adsorption of TC by rGO was 6 hours (Fig.

253 5a). The initial $\mathrm{pH}$ of $\mathrm{TC}$ solutions was prepared in the range of 2-10 to study the impact of the $254 \mathrm{pH}$ value on the adsorption of TC onto rGO. When the initial $\mathrm{pH}$ value increased from 2 to 7 , the 255 adsorption capacity of rGO material augmented, reaching the maximum value of $30.92(\mathrm{mg} / \mathrm{g})$ at $256 \mathrm{pH}$ (Fig. 5b). This could be explained by the fact that when the $\mathrm{pH}<4$, the TC molecules were 257 fully protonated [20] while rGO surfaces were positively charged as the $\mathrm{pH}_{\mathrm{pzc}}$ of $\mathrm{rGO}=5.2$, which 258 would inhibit the accumulation of TC on the surfaces of rGO due to the electrostatic repulsive 
259 force. In the range of $\mathrm{pH} 4-\mathrm{pH} 7$, the $\mathrm{TC}$ was in the form of zwitterion +-0 , the interaction 260 between rGO and TC molecules was impacted by both electrostatic repulsion and attraction forces.

261 As a result, the adsorption of TC molecules on rGO was controlled by the stronger one. In $\mathrm{pH}>$ 2627.7 solutions, TC was in the form of monovalent anion, +-- , or a divalent anion, $0--[15,41]$.

263 This explained a decline in adsorption capacity of $\mathrm{rGO}$ in the $\mathrm{pH} \geq 8$ solutions (Fig. 5b) due to the 264 electrostatic repulsion between rGO surface negatively charged and TC anions.
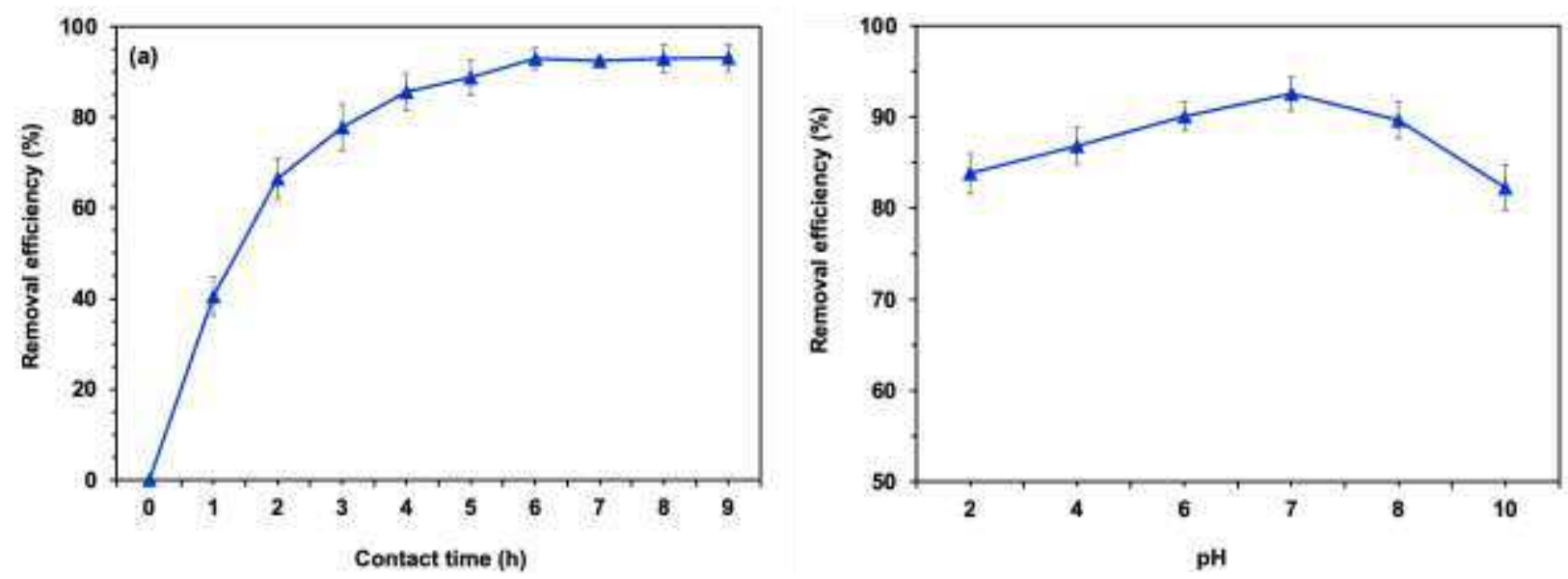

265

266

267

Fig. 5 Effect of (a) contact time and (b) $\mathrm{pH}$ on the removal eficiency of rGO (adsorption conditions: $\left.[\mathrm{TC}]=5 \mathrm{mg} / \mathrm{L}, \mathrm{pH}=6.5, \mathrm{~m}_{\mathrm{rGO}}=10 \mathrm{mg}, \mathrm{V}=100 \mathrm{~mL}\right)$.

In addition to electrostatic interactions between $\mathrm{rGO}$ and $\mathrm{TC}$ molecules, the competitive adsorption between $\mathrm{H}^{+}$and TC in acidic solutions and between $\mathrm{OH}^{-}$and $\mathrm{TC}$ in basic medium, the $\pi-\pi$ interactions between TC and the aromatic structure of rGO dramatically enhanced the adsorption energy of rGO and TC, leading to an improvement of adsorption capacity [20].

\subsubsection{Effect of adsorbent dosage}

The adsorbent dosage might affect the adsorption process because it supplies more available sites for TC molecules to be adsorbed. The results in Fig. 6a show that the adsorption capacity decrease in correlation with an increase in adsorbent load from $50 \mathrm{mg} / \mathrm{L}$ to $100 \mathrm{mg} / \mathrm{L}$. The maximum uptake reached $46.29 \mathrm{mg} / \mathrm{g}$, corresponding to the adsorbent load of $100 \mathrm{mg} / \mathrm{L}$. 

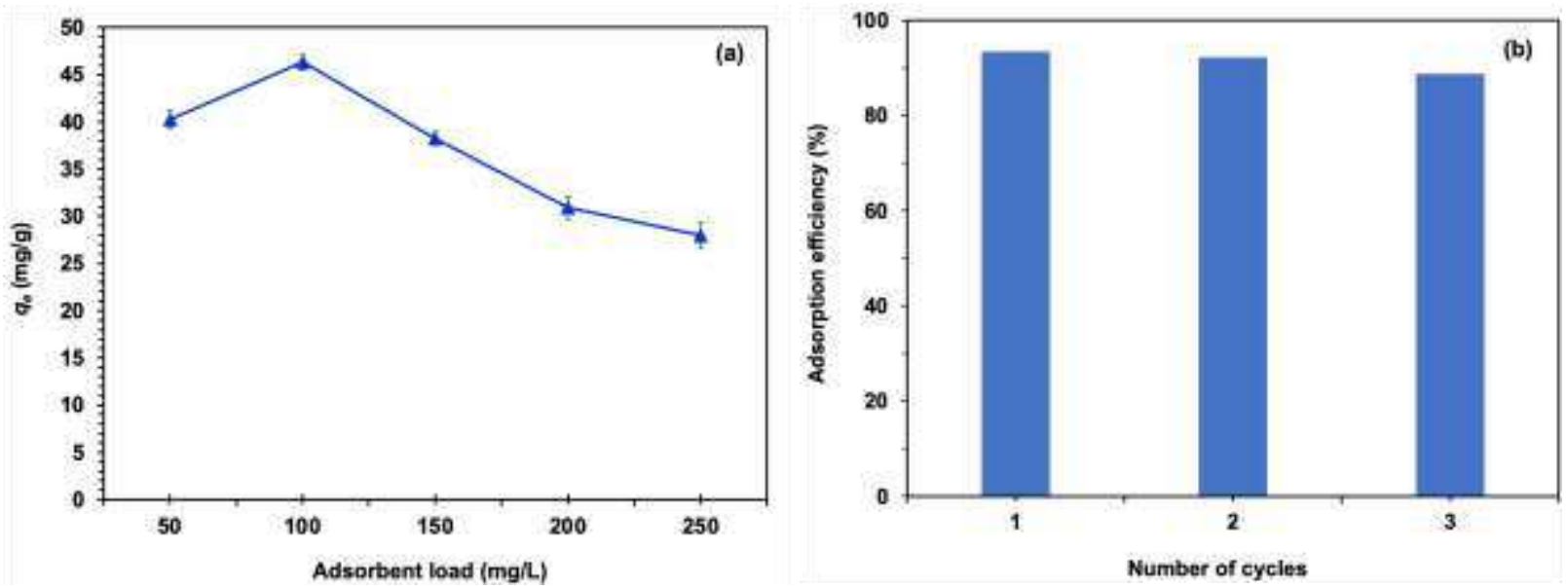

278

Fig. 6 (a) Effect of adsorbent dosage on TC removal by rGO, and (b) regeneration of rGO (adsorption conditions: $[\mathrm{TC}]=5 \mathrm{mg} / \mathrm{L}, \mathrm{pH}=7.0, \mathrm{~m}_{\mathrm{rGO}}=10 \mathrm{mg}, \mathrm{V}=100 \mathrm{~mL}$ ).

When the adsorbent dose exceeded $100 \mathrm{mg} / \mathrm{L}$, the adsorption capacity of rGO declined. These observations could be explained as 1) the total surface area became more important when rGO concentration increased, leading to better adsorption capacity. However, when the amount of the adsorbent exceeded $100 \mathrm{~m} / \mathrm{L}$, the aggregation of rGO sheets due to $\pi-\pi$ interactions occurred, which could contribute to a decline in total surface area. This results in a lower TC removal efficiency $[42,43]$.

\subsubsection{Effect of initial concentration of TC: adsorption isotherms}

The results in Fig 7a reveal that the higher the initial concentration of TC the better removal capacity. This observation could be attributed to (1) at lower TC concentrations, the mass transfer of TC molecules and the adsorbed fraction of ions became low, resulting in lower adsorption capacity; (2) when the TC concentration increased, the increase in mass the transfer of TC molecules led to a higher fraction of molecules occupied the available adsorption sites on the surface of materials, therefore increasing the adsorption yield. When the TC concentration achieved a limit value (around 60-70 mg/L), the number of unoccupied active sites might decrease, leading to a decline in adsorption capacity. 

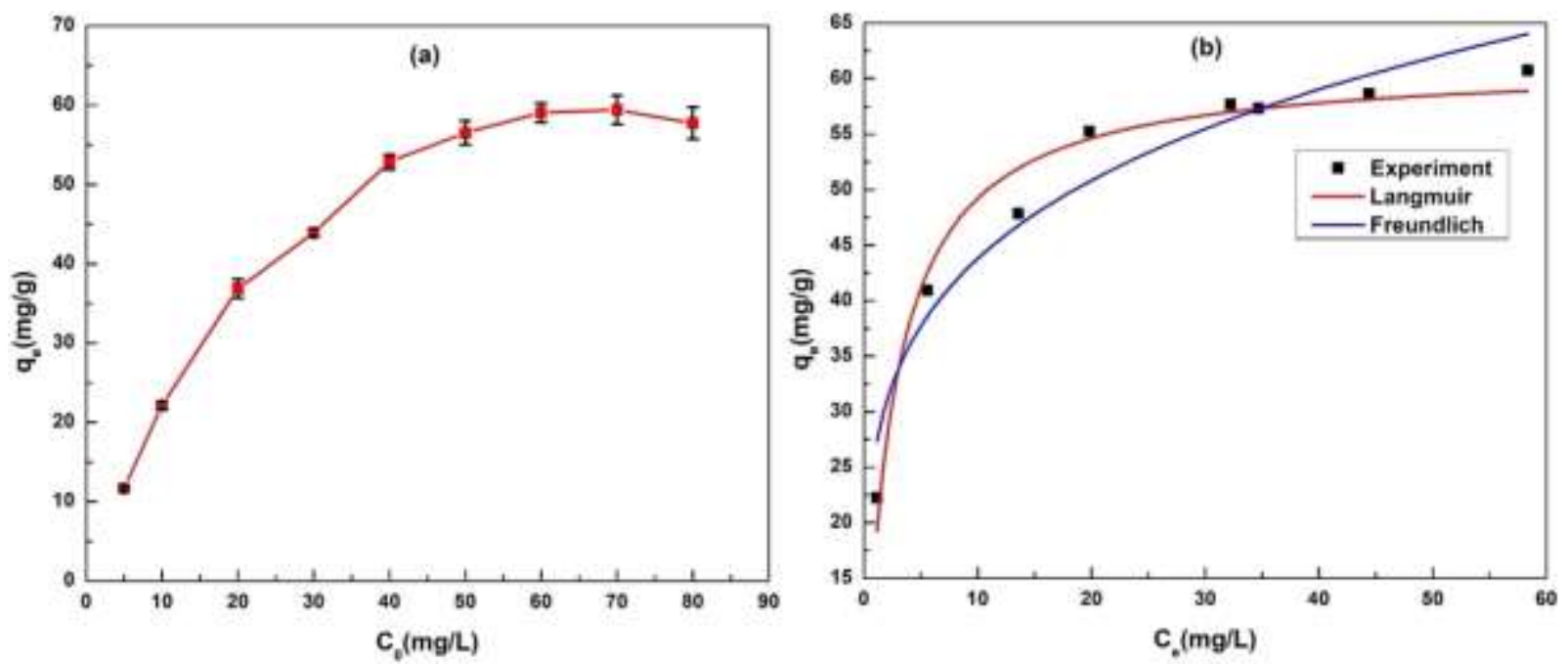

Fig. 7 (a) Effect of initial concentration of TC, and (b) adsorption isotherms (adsorption conditions: $[\mathrm{TC}]=5-80 \mathrm{mg} / \mathrm{L}, \mathrm{pH}=7, \mathrm{~m}_{\mathrm{rGO}}=10 \mathrm{mg}, \mathrm{V}=100 \mathrm{~mL}$ ).

The experimental results were subsequently subjected to two adsorption isotherm models (Langmuir and Freundlich) for studying the adsorption isotherm. The obtained results in Fig. 7b depicted that the Langmuir model better described the adsorption of TC on rGO than the Freundlich model. This was supported by the slightly higher regression coefficient $\left(\mathrm{R}^{2}\right)$ by the Langmuir model than the one obtained by the Freundlich model (0.986 vs 0.942$)$. This suggested that chemisorption with monolayer was more importantly governing the adsorption process. The maximum adsorption uptake calculated by Langmuir model achieved $58.03 \mathrm{mg} / \mathrm{g}$. The obtained result in this work was higher than the one $(13.27 \mathrm{mg} / \mathrm{g})$ obtained from the adsorption of TC onto biochar [44] but lower than the result $(313 \mathrm{mg} / \mathrm{g})$ obtained from the adsorption of TC onto GO [17]. This could be explained by different functional groups $(-\mathrm{OH},-\mathrm{C}=\mathrm{O},-\mathrm{COOH},-\mathrm{O}-)$ on the surface of GO, which might facilitate the accumulation of TC molecules by electrostatic attraction forces [24]. 


\subsubsection{Effect of temperature}

313 The effect of temperature was examined with $298 \mathrm{~K}, 308 \mathrm{~K}$, and $318 \mathrm{~K}$. The adsorption capacities

314 at the selected temperatures were compared at the equilibrium condition (6 hours). The

315 experimental data revealed that the adsorption capacity was positively proportional to the

316 temperature (Fig 8). For instance, the adsorption capacity of rGO for the removal of $80 \mathrm{mg} / \mathrm{L} \mathrm{TC}$

317 solutions at $298 \mathrm{~K}, 308 \mathrm{~K}, 318 \mathrm{~K}$ respectively reached $60.76,107.33$ and $137.41 \mathrm{mg} / \mathrm{g}$ while these

318 values for $10 \mathrm{mg} / \mathrm{L} \mathrm{TC}$ solutions were $40.95 \mathrm{mg} / \mathrm{g} ; 43.13 \mathrm{mg} / \mathrm{g}$; and $43.30 \mathrm{mg} / \mathrm{g}$, respectively. This

319 implied that the adsorption process would be endothermic in case it was associated with reversible

320 adsorption.

321

322

323

324

325

326

327

328
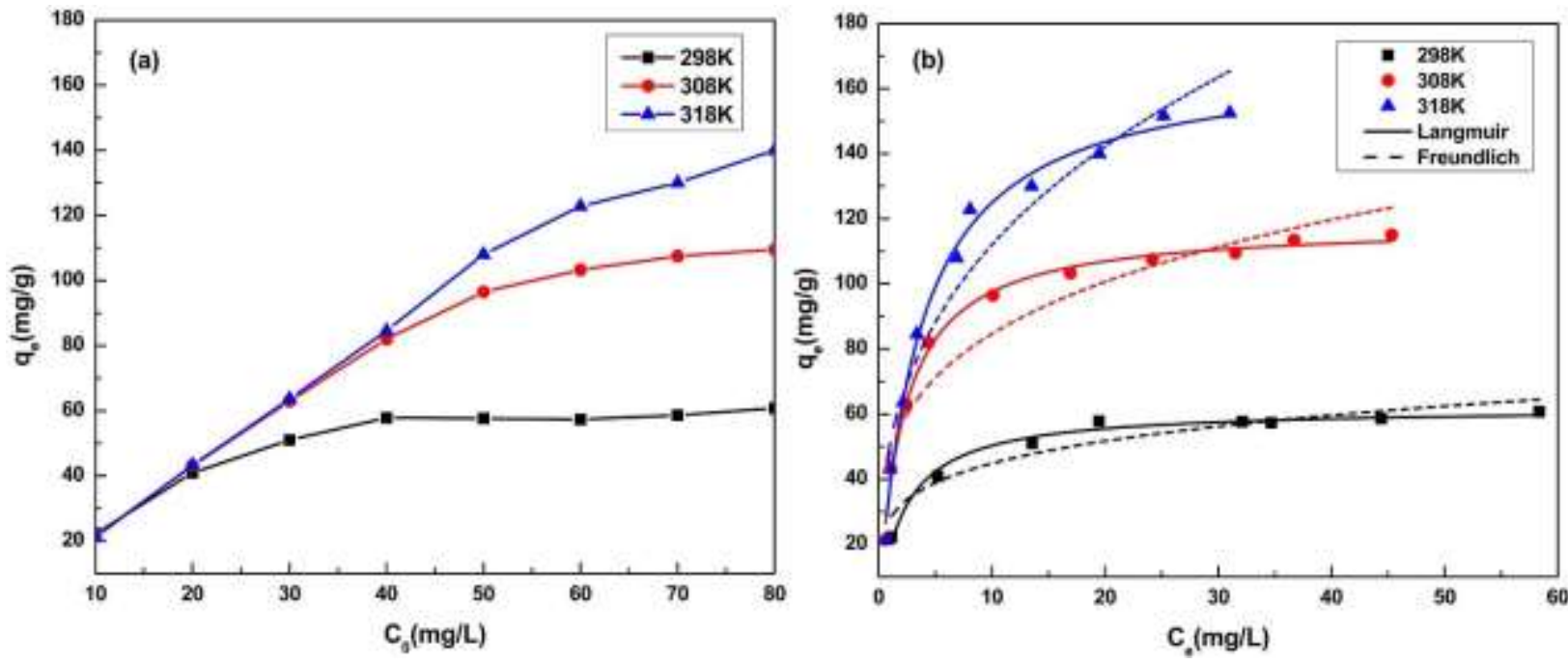

Fig. 8 (a) effect of temperature on the TC adsorption, (b) adsorption isotherms at different temperature (conditions: $[\mathrm{TC}]=5-80 \mathrm{mg} / \mathrm{L}, \mathrm{pH}=7.0, \mathrm{~m}_{\mathrm{rGO}}=10 \mathrm{mg}, \mathrm{V}=100 \mathrm{~mL}$ ).

\subsubsection{Adsorption kinetics}

The results were better fitted with the pseudo-first-order model than the pseudo-secondorder (regression coefficient $\left(\mathrm{R}^{2}\right)=0,991$ for the pseudo-second-order model compared with $\mathrm{R}^{2}=$ 0,998 for the pseudo-first-order model). In addition, the percentage deviations of $q_{\mathrm{e}}$ for the pseudofirst-order model was significantly lower than that obtained from the pseudo-second order model 
329 (4.91\% vs 34.2\%), implying physisorption was predominant in the TC adsorption process (Table

330 2). The constant rate $\mathrm{K}$ estimated from the first-order model was $0.6356 \mathrm{~h}^{-1}$. Table 2 also compares

331 the constant rate of different materials used for TC adsorption. It indicated that the adsorption rate

332 of rGO was higher than graphite and other materials such as pumice and biochar, but lower than

333 GO probably due to a number of oxygen-containing functional groups on the surface of GO, which

334 enhanced the adsorption of TC molecules by ion exchange and/or electrostatic attraction forces $335[24]$.

336 Table 2. Comparison of kinetic parameters of different materials in the adsorption of TC.

\begin{tabular}{|c|c|c|c|c|c|c|c|}
\hline & \multirow{2}{*}{ Kinetic models } & \multicolumn{6}{|c|}{ Adsorbents } \\
\hline & & rGO & Graphite & Biochar & GO & rGO & Pumice \\
\hline \multirow{5}{*}{ 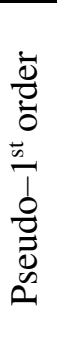 } & $\mathrm{q}_{\mathrm{e}}($ experimental $)$ & 46.54 & 33.01 & 6.42 & 38.03 & 37.5 & 2.83 \\
\hline & $\mathrm{q}_{\mathrm{e}}(\mathrm{mg} / \mathrm{g})$ & 48.71 & 31.51 & 3.27 & - & - & 2.93 \\
\hline & $\mathrm{K}\left(\mathrm{h}^{-1}\right)$ & 0.6356 & 0.014 & 0.081 & - & - & 0.05 \\
\hline & $\mathrm{R}^{2}$ & 0.998 & 0.99 & 0.877 & - & - & 0.99 \\
\hline & $\% \Delta \mathrm{q}_{\mathrm{e}}$ & 4.91 & 4.5 & 48.9 & - & - & 3.6 \\
\hline \multirow{4}{*}{ 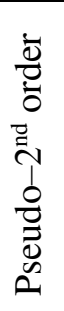 } & $\mathrm{q}_{\mathrm{e}}(\mathrm{mg} / \mathrm{g})$ & 62,50 & - & 7.01 & 35,03 & 44.23 & 2.99 \\
\hline & $\mathrm{K}\left(\mathrm{g} \cdot \mathrm{mg}^{-1} \cdot \mathrm{h}^{-1}\right)$ & 0.017 & - & 0.069 & 0.065 & 5.4 & 0.049 \\
\hline & $\mathrm{R}^{2}$ & 0.991 & - & 0.99 & 0.99 & 0.991 & 0.98 \\
\hline & $\% \Delta \mathrm{q}_{\mathrm{e}}$ & 34.20 & - & 9.4 & 7.9 & 17.9 & 6.8 \\
\hline \multirow{4}{*}{ 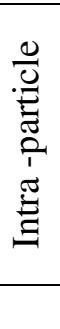 } & $\mathrm{K}_{\mathrm{d}}\left(\mathrm{mg} \cdot \mathrm{g}^{-1} \cdot \mathrm{h}^{-0.5}\right)$ & 0.0637 & - & - & - & - & - \\
\hline & $\mathrm{C}\left(\mathrm{mg} \cdot \mathrm{g}^{-1}\right)$ & 0.7591 & - & - & - & - & - \\
\hline & $\mathrm{R}^{2}$ & 0,987 & - & - & - & - & - \\
\hline & References & This study & [45] & {$[44]$} & [17] & [24] & [46] \\
\hline
\end{tabular}




\subsubsection{Adsorption thermodynamics and regeneration of adsorbent}

To assess energy exchange phenomenon of the TC sorption process, Gibbs free energy

$341(\Delta \mathrm{G})$, enthalpy $(\Delta \mathrm{H})$, and entropy $(\Delta \mathrm{S})$ were estimated. $\Delta \mathrm{G}$ values were negative at all temperature $342(-7.79,-9.31$, and $-9.54 \mathrm{~kJ} / \mathrm{mol}$ for 298,308 , and $318 \mathrm{~K})$ which confirmed the spontaneous nature 343 of the adsorption of TC onto rGO (Table 3).

Table 3. Thermodynamic parameters of TC adsorption process onto rGO.

\begin{tabular}{cccc}
\hline Temperature $(\mathbf{K})$ & $\boldsymbol{\Delta G}(\mathbf{k J} / \mathbf{m o l})$ & $\Delta \mathbf{H}(\mathbf{k J} / \mathbf{m o l})$ & $\Delta \mathbf{S}\left(\mathbf{k J} \cdot \mathbf{m o l}^{\left.-\mathbf{1} \cdot \mathbf{K}^{-\mathbf{1}}\right)}\right.$ \\
\hline 298 & -7.79 & & \\
308 & -9.31 & 17.97 & 0.087 \\
318 & -9.54 & & \\
\hline
\end{tabular}

In general, the adsorption enthalpy in the range of 2 to $20 \mathrm{~kJ} / \mathrm{mol}$ characterizes physical 347 adsorption. The positive value of $\Delta \mathrm{H}(17.97 \mathrm{~kJ} / \mathrm{mol})$ confirmed that the adsorption process was 348 endothermic and physisorption (Table 3). It was noted that the results of adsorption isotherm 349 revealed that chemisorption with monolayer was more important process while the results on 350 adsorption thermodynamics and kinetics indidated physisorption played a more important role than 351 chemisorption; therefore, it could be concluded that the TC adsorption onto rGO was of both 352 physisorption and chemisorption. The positive value of $\Delta \mathrm{S}\left(87 \mathrm{~J} \cdot \mathrm{mol}^{-1} \cdot \mathrm{K}^{-1}\right)$ reflected an increase 353 in the disorder and randomness at rGO-solution interfaces during the sorption of TC.

354 It is noted that the successive desorption-adsorption trial was repeated three times in which 355 adsorption test was performed at optimal conditions (10 mg rGO, $5 \mathrm{mg} / \mathrm{L} \mathrm{MB}$ solution (pH=7), 356 and a contact time of 6 hours). The adsorption efficiency remained very high (> 89\%) after three 
357 cycles for TC adsorption (Fig 6b). This suggests that methanol and $0.1 \mathrm{M} \mathrm{NaOH}$ solutions could 358 be deployed to regenerate rGO for further adsortion process.

\section{Conclusions}

The reduced graphene oxide was successfully synthesized using chemical reduction process with the aid of $\mathrm{L}$ - ascorbic acid as the reducing agent. Effects of different parameters on the adsorption of TC onto rGO material such as contact time, temperature, $\mathrm{pH}$ of the solution, 364 adsorbent dosage, and TC initial concentration were studied. The optimal conditions for the 365 adsorption of TC onto rGO were 6 hours, $\mathrm{pH}=7$, adsorbent load $=100 \mathrm{mg} / \mathrm{L}$, TC initial 366 concentration $=60 \mathrm{mg} / \mathrm{L}$. The TC adsorption process was better described by the pseudo-first367 order model and the Langmuir adsorption isotherm model. The maximum uptake calculated by 368 Langmuir model was $58.03 \mathrm{mg} / \mathrm{g}$. The TC adsorption process was spontaneous, endothermic. Both 369 chemisorption and physisorption mechanisms occurred during the TC adsorption process. The 370 recovery and reuse of rGO could be performed by using methanol and diluted $\mathrm{NaOH}$ solutions, 371 with a decrease of about $6 \%$ in adsorption efficiency after 3 cycles. This research revealed that the 372 rGO was a promising material for the removal of TC from solutions.

374 Data availability

375 All data generated or analyzed during this study are included in this published article.

\section{Conflicts of Interest Declaration}

378 The authors declare that they have no known competing financial interests or personal 379 relationships that could have appeared to influence the work reported in this paper. 


\section{References}

1. R. Gothwal, T. Shasidhar, Clean (Weinh) 43, 479-489 (2015). https://doi.org/10.1002/clen.201300989.

2. T.P. van Boeckel, C. Brower, M. Gilber, B.T. Grenfell, S.A. Levin, T.P. Robinson, Proc. Natl. Acad. Sci. U.S.A 112, 5649-5654 (2015). https://doi.org/10.1073/pnas.1503141112.

3. T.P. van Boeckel, E.E. Glennon, D. Chen, M. Gilbert, T.P. Robinso, B.T. Grenfel, S.A. Levin, S. Bonhoeffer, R. Laxminarayan, Science. 357, 1350-1352 (2017). https://doi.org/10.1126/science.aao1495.

4. T. Beek, F.A. Weber, A. Bergmann, S. Hickmann, I. Ebert, A. Hein, A. Kuster, Environ. Toxicol. Chem. 35, 823-835 (2016). https://doi.org/10.1002/etc.3339.

5. M. Xua, J. Deng, A. Cai, X. Ma, J. Li, Q. Li, X. Li, Chem. Eng. J. 384, 123320 (2020). https://doi.org/10.1016/j.cej.2019.123320.

6. A. Cai, J. Deng, M. Xu, T. Zhu, S. Zhou, J. Li, G. Wang, X. Li, Chem. Eng. J. 395, 125090 (2020). https://doi.org/10.1016/j.cej.2020.125090.

7. B. Daghrir, P. Drogui, Environ. Chem. Lett. 11 209-227 (2013). https://doi.org/10.1007/s10311-013-0404-8.

8. Y. Chen, Y. Niu, T. Tian, J. Zhang, Y. Wang, Y. Li, L.C. Qin, Chem. Phys. Lett. 677, 143-147 (2017). https://doi.org/10.1016/j.cplett.2017.04.002.

9. X.S. Miao, F. Bishay, M. Chen, C.D. Metcalfe, Environ. Sci. Technol. 38 3533-3541 (2004). https://doi.org/10.1021/es030653q.

10. A. Javid, A. Mesdaghinia, S. Nesseri, A.M. Mahvi, M. Alimohammadi, H. Gharibi, J. Environ. Health Sci. Eng. 14, 4 (2016). https://doi.org/10.1186/s40201-016-0245-Z. 
11. Oh S-H, Jeong S, Kim I. S, Shon H. K, Jang A, J. Environ. Manage. 247, 385-393 (2019). https://doi.org/10.1016/j.jenvman.2019.06.070.

12. Y. Li, X. Lin, C. Zhang, Q. Zhuang, W. Dong, Colloids Surf. A Physicochem. Eng. Asp. 628, 127263 (2021). https://doi.org/10.1016/j.colsurfa.2021.127263

406

13. M.S.A. Hussien, J. Inorg. Organomet. Polym. 31, 945-959 (2021). https://doi.org/10.1007/s10904-020-01831-z

14. Y. Duan, Y. Cao, X. Shang, D. Jia \& C. Li, J. Inorg. Organomet. Polym. 31, 2140-2149 (2021). https://doi.org/10.1007/s10904-021-01923-4

15. D.T Tran, V.N Nguyen, Mater. Res. Express 7, 075501 (2020). https://doi.org/10.1088/2053-1591/ab9e47

16. V.C. Dang, D.T. Tran, A.T. Phan, N.K. Pham, V.N. Nguyen, J. Phys. Chem. Solids 153, 110005 (2021). https://doi.org/10.1016/j.jpcs.2021.110005

17. Y. Gao, Y. Li, L. Zhang, H. Huang, J. Hu, S.M. Shah, X. Su, J. Colloid Interface Sci. 368, 415 540-546 (2012). https://doi.org/10.1016/j.jcis.2011.11.015. 
22. Y. Ai, Y. Liu, Y. Huo, C. Zhao, L. Sun, B. Han, X. Cao, X. Wang, Environ. Sci. Nano 6, 3336-3348 (2019). https://doi.org/10.1039/C9EN00866G

23. P.V. Nidheesh, Environ. Sci. Pollut. Res. 24, 27047-27069 (2017). https://doi.org/10.1007/s11356-017-0481-5

24. A.M. Huízar-Félix, C. Aguilar-Flores, A.M. Cruz, J.M. Barandiarán, S. SepúlvedaGuzmán, R. Cruz-Silva, Nanomaterials $\quad 9, \quad 313 \quad$ (2019). https://doi.org/10.3390/nano9030313.

25. W. Song, T. Yang, X. Wang, Y. Sun, Y. Ai, G. Sheng, T. Hayat, X. Wang, Environ. Sci. Nano 3, 1318-1326 (2016). https://doi.org/10.1039/C6EN00306K.

26. M. Aleksandrzak, D. Moszyński, E. Mijowska, J. Colloid Interface Sci. 496, 188-200 (2017). https://doi.org/10.1016/j.jcis.2017.02.031

27. J. Dai, X. Meng, Y. Zhang, Y. Huang, Bioresour. Technol. 311, 123455 (2020). https://doi.org/10.1016/j.biortech.2020.123455.

28. Z.J. Fan, W. Kai, J. Yan, T. Wei, L.J. Zhi, J. Feng, Y. Ren, L.P. Song, F. Wei, ACS Nano 5, 191-198 (2011). https://doi.org/10.1021/nn102339t.

29. J. Yan, Z. Fan, T. Wei, W. Qian, M. Zhang, F. Wei, Carbon 48, 3825-3833 (2010). https://doi.org/10.1016/j.carbon.2010.06.047.

30. H.M.A. Hassan, V. Abdelsayed, A.E.R.S. Khder, K.M.A. Zeid, J. Terner, M.S. El-Shall, S.I. Al-Resayes, A.A. El-Azhary, J. Mater. Chem. 19, 3832-3837 (2009). https://doi.org/10.1039/B906253J.

31. V.N. Nguyen, D.T. Tran, M.T. Nguyen, T.T.T. Le, M.N. Ha, M.V. Nguyen, T.D. Pham, Res. Chem. Intermed. 44, 3081-3095 (2018). https://doi.org/10.1007/s11164-018-3294-3 
32. F.T. Johra, W.G. Jung, Appl. Surf. Sci. 357, 1911-1914 (2015). https://doi.org/10.1016/j.apsusc.2015.09.128.

33. C. Xu, X. Shi, A. Ji, L. Shi, C. Zhou, Y. Cui, PloS ONE 10, 0144842 (2015). https://doi.org/10.1371/journal.pone.0144842.

34. Z. Yang, Q. Zheng, H. Qiu, J. Li, J. Yang, New Carbon Mater. 30, 41-47 (2015). https://doi.org/10.1016/S1872-5805(15)60174-3.

35. L.G. Guex, B. Sacchi, K.F. Peuvot, R.L. Andersson, A.M. Pourrahimi, V. Strom, S. Farris, R.T. Olsson, Nanoscale 9, 9562-9571 (2017). https://doi.org/10.1039/C7NR02943H

36. P.G. Ren, D.X. Yan, X. Ji, T. Chen, Z.M. Li, Nanotechnology 22, 055705 (2010). http://dx.doi.org/10.1088/0957-4484/22/5/055705.

37. K.B. Narayanan, H.D. Kim, S.S. Han, Colloids Surf. B 185, 110579 (2020). https://doi.org/10.1016/j.colsurfb.2019.110579.

38. Z. Fan, K. Wang, T. Wei, J. Yan, L. Song, B. Shao, Carbonn 48, 1686-1689 (2010). https://doi.org/10.1016/j.carbon.2009.12.063.

39. P. Montes-Navajas, N.G. Asenjo, R. Santamaría, R. Menéndez, A. Corma, H. García, Langmuir 29, 13443-13448 (2013). https://doi.org/10.1021/la4029904

40. H. Moussa, E. Girot, K. Mozet, H. Alem, G. Medjahdi, R. Schneider, Applied Catalysis B: Environmental 185, 11-21 (2016). https://doi.org/10.1016/j.apcatb.2015.12.007.

41. A. Amat, S. Fantacci, F.D. Angelis, B. Carlotti, F. Elisei, Chem. Acc. 131, 1218 (2012). https://doi.org/10.1007/s00214-012-1218-7.

42. K.S. Padmavathy, G. Madhu, P.V. Haseena, Procedia Technol. 24, 585-594 (2016). https://doi.org/10.1016/j.protcy.2016.05.127.

43. P. Wang, J. Environ. Sci. 56, 202-213 (2017). https://doi.org/10.1016/j.jes.2016.04.032. 
44. H. Wang, C. Fang, Q. Wang, Y. Chu, Y. Song, Y. Chen, X. Xue, RCS Adv. 8, 16260470 16268 (2018). https://doi.org/10.1039/C8RA01454J.

471

45. M.D. Vedenyapina, D.A. Borisova, A.K. Rakisev, A.A. Vedenyapin, Solid Fuel Chem.

472 48, 323-327 (2014). https://doi.org/10.3103/S0361521914050139.

473

46. J. Lu, K. Xu, W. Li, D. Hao, L. Qiao, Water Qual. Res. J. Canada 53, 143-155 (2018).

474 https://doi.org/10.2166/wqrj.2018.012. 